\title{
The employment concerns of Americans with multiple sclerosis: Perspectives from a national sample
}

\author{
Phillip D. Rumrill, Jr. ${ }^{\mathrm{a}, *}$, Richard T. Roessler ${ }^{\mathrm{b}},{\text { Jian } \mathrm{Li}^{\mathrm{c}} \text {, Katherine Daly }{ }^{\mathrm{a}} \text { and Mykal Leslie }}^{\mathrm{a}}$

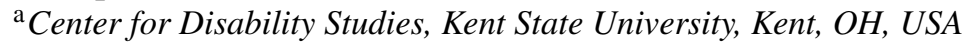 \\ ${ }^{\mathrm{b}}$ Independent Rehabilitation Consultant, Fayetteville, AR, USA \\ ${ }^{\mathrm{c}}$ School of Foundations, Leadership, and Administration, Kent State University, Kent, OH, USA
}

Received 1 January 2015

Accepted 25 August 2015

\begin{abstract}
.
BACKGROUND: The recent rehabilitation literature does not include a thorough assessment of the employment concerns of people with MS.

OBJECTIVE: This article presents descriptive findings from a national survey of the employment concerns of Americans with multiple sclerosis (MS; $N=1,924$ ), representing nine chapters of the National Multiple Sclerosis Society.

METHODS: Respondents were asked to evaluate 38 employment concerns items on two dimensions, importance and satisfaction, for the purpose of identifying strengths and weaknesses in the employment policies and practices affecting the labor force participation of people with MS.

RESULTS: Results revealed a total of 32 employment strengths and six employment weaknesses.

CONCLUSIONS: In spite of a jobless rate of more than 60 percent, people with MS were satisfied with the majority of employment concerns. Implications of these findings for rehabilitation policy and service delivery are examined.
\end{abstract}

Keywords: Chronic illness, career development, vocational rehabilitation

\section{Introduction}

The purpose of this investigation was to identify the "problematic mediating and contextual factors" $[1, p$. 173] that influence the employment outcomes of adults with multiple sclerosis (MS) and to recommend interventions to deal with those factors. In the past, much of the research on MS and employment has focused on the demographic and illness-related characteristics of individuals, with less attention given to workplace, service

*Address for correspondence: Phillip Rumrill, Kent State University, P.O. box 5190, 413 White Hall, Kent, OH 44242-0001, USA. Tel.: +330 672 0600; Fax: +330 672 2512; E-mail: prumrill@ kent.edu. delivery, and social policy considerations [2]. Although many of the demographic and illness-related aspects of the person are not easily changed, the contexts within which adults with MS function (i.e., workplace, rehabilitative service agencies, and social programs) are, potentially resulting in improved job acquisition and maintenance outcomes. The need to address remediable barriers to employment in the environment is evident in the high unemployment rates of adults with MS [3, 4].

\subsection{Employment outcomes and MS}

The person's employment status is one of the alltoo-frequent casualties of multiple sclerosis. Although the vast majority of people with MS have employment 
histories and most were working at the time of diagnosis, the onset and continuation of the disease prompt what appears to be a mass exodus from the labor force. The majority of people with MS are no longer working 5 years post diagnosis, and the overall employment rate for people with MS hovers between 30 and 45 percent [5]. Encouraging advances in the medical and pharmaceutical sciences have enabled many people with MS to live healthier, fuller, and more active lives than ever before, but improvements in functional capabilities for many people with MS have not translated directly into improved employment outcomes.

For many years, medical, psychological, allied health, and rehabilitation researchers have sought to understand why so many people with MS disengage from the labor force, usually of their own choosing, and often before the disease has rendered them incapable of working. Indeed, among people with MS who are unemployed, 75 percent left their jobs voluntarily [6], 80 percent believe that they retain the ability to work [7], and 75 percent say that they would like to re-enter the work force [8]. As previously noted, in explanations of the wholesale disengagement from work associated with MS, demographic and diseaserelated factors have played a prominent role. However, the focus of this investigation is on the contemporary workplace, service delivery, and social policy conditions that influence the employment status of adults with MS.

\subsubsection{Demographic factors}

Age and gender are two demographic variables that predict employment outcomes for adults with MS [9-16]. Typically, older minority group individuals with MS are less likely to be employed. Results are mixed regarding the impact of gender, with women with MS more likely to be unemployed than men in some studies but not in others [4, 11, 13, 17]. Both men and women with MS are more likely to leave the work force if they have a spouse who is working [18]. People with MS who have higher levels of education and/or more money in savings and investments are more likely to be employed than are those in lower socioeconomic strata $[10,19]$. This finding may not be surprising given that people with higher levels of education tend to occupy positions that require less physical exertion, and the physiological effects of MS therefore may not impose work impediments to the extent that they do for those whose jobs require more physical exertion. Similarly, Smith and Arnett [20] reported that individuals with MS holding higher occupational statuses had the flexibility and, most probably, the authority to maintain employment by cutting back on their work duties and hours.

\subsubsection{Disease-related factors}

Several studies have revealed the exacerbation and progression of physical symptoms to be strong predictors of job loss [14, 21]. In denoting the most frequently cited reasons that people with MS leave the work force, Rumrill [8] and Fraser et al. [22] noted that as many as 30 percent of unemployed people with MS attribute their jobless status to the physiological effects of the illness, especially fatigue. Nearly half of unemployed respondents in a survey of people with MS conducted by Edgley et al. [23] cited ambulation difficulties as the primary reason for leaving the work force. Thirty-nine percent described fatigue as the most important contributing factor. Bishop et al. [12] reported that people with MS whose physical disabilities compromised the accessibility of their home environments and/or their ability to travel independently were at much greater risk for job loss than were people with MS who have more accessible homes and transportation options.

Roessler et al. [19] found that people who experience MS symptoms most or all of the time, especially if the persistent symptoms are greater in number and more severe, are more likely to be unemployed than people with other symptom patterns. More symptoms, more persistent symptoms, and more severe symptoms are generally associated with primary or secondary progressive MS, so it follows that people with progressive forms of the disease are at greater risk for job loss than people whose MS experience is more episodic and/or less intrusive.

Cognitive deficits associated with MS are one of the most frustrating aspects of the illness [22, 24-26]. By their own reports, employees with MS identified significant career maintenance barriers and resultant needs for on-the-job accommodations related to thoughtprocessing and memory deficits in a study conducted by Rumrill, Fraser, and Johnson [27]. Roessler et al. [19] found people with MS who reported cognitive impairments four times more likely to be unemployed than people with MS who did not report cognitive impairments.

People with MS often experience affective disorders and psychological problems that can affect their prospects for continued employment. In a recent followup study of the on-the-job accommodation patterns of employed people with MS, Rumrill et al. [27] found that workers with MS had the most difficulty arranging 
workplace accommodations to address depression, anxiety, and bipolar disorder. Relatedly, Krause et al. [14] also found that individuals reporting higher depressive symptom levels were more likely to be unemployed.

\subsubsection{Contextual factors}

The previous discussion summarized the well-known impact of the more unchangeable demographic and physiological characteristics on the employment outcomes of individuals with MS. However, the intent of this research was to investigate contemporary contextual factors influencing the employment status of adults with MS and to examine strategies for ameliorating perceived barriers to employment in workplace, rehabilitative service, and social programs. Past research provides insights into the types of environmental conditions requiring attention.

Ketelaer et al. [28] reported that people with MS employed in the medical field and in jobs that required them to work out-of-doors, stand for long periods of time, and/or exert physical strength were far more likely to lose their jobs than were those working under other occupational conditions. Duggan et al. [29] simply asked unemployed people with MS why they had left their jobs. Approximately 75 percent reported stopping work voluntarily, but worksite barriers were frequently cited as reasons for that choice. These on-the-job obstacles included less-than-helpful employee assistance programs and a lack of reasonable accommodations. Many respondents believed that they could have benefited from such assistance as homebased work, education for their employers about MS, and individual employment counseling. A number of respondents also felt that information concerning the Americans with Disabilities Act (ADA), other legal protections, health insurance, and Social Security Disability Insurance would have helped them to retain employment.

Supportive of the need for contemporary research regarding the way in which perceptions of contextual barriers change, Rumrill et al. [30] reported survey results for 227 adults with MS in a mid-western state in which respondents were satisfied with their access to adequate health insurance. They also were satisfied with other employment supports, e.g., encouragement to take control of their lives, access to similar benefits at work as other workers (e.g., compensation), support regarding personal potential to work, and availability of reasonable accommodations at work. In the Rumrill et al. [30] survey, adults with MS identified the following areas as deficiencies in employment programs and policies: protection against discrimination in the hiring process; access to service providers who are knowledgeable about the needs of people with MS; availability of adequate information about Social Security programs; assistance in making plans for the future; access to employers to discuss reasonable accommodation needs; adequate information about funding for assistive devices at work; and the availability of retraining, if needed to return to work.

Again underscoring the need for contemporary research, other studies document that, across time, people with MS are not always in agreement when it comes to identifying employment strengths. In fact, in these studies, areas referred to as employment strengths in other reports were singled out as employment deficiencies. For example, people with MS in Jackson and Quaal's [31] survey and in O'Day's [32] qualitative study reported a lack of employer support and difficulties accessing reasonable accommodations at work (i.e., employment deficiencies).

Information reported by LaRocca et al. [33] and Jackson and Quaal [31] corroborated findings in the Rumrill et al. [30] survey. In those studies, people with MS indicated that they were not well prepared to return to work and expressed desires for additional training. Individuals with MS identified other deficiencies inherent in employment services. For example, people with MS were concerned about the lack of workplace protections such as those included in Title I of the Americans with Disabilities Act (ADA). In one study predating implementation of the ADA, respondents indicated that they needed greater (a) flexibility in their work hours and work settings (e.g., work at home), (b) availability of assistive technology at work, and (c) physical accessibility of the work environment [31]. In calling for more research to identify barriers to employment for people with MS, Jackson and Quaal [31] reported another weakness in employment services for workers with MS, namely the lack of periodic on-the-job follow-up and support services for employees who are coping with chronic illnesses such as MS (see also [34, 35] for a discussion of the need for job retention services).

Though the choice to leave the work force is most often made by the person with MS himself or herself, it is not entirely clear to what extent the phenomenon of discrimination in the workplace affects that choice. What is known is that perceived discrimination is a major obstacle to continued employment following diagnosis with MS, and that people with MS often believe that their employers treat them unfairly in comparison to workers without disabilities. In the national 
survey conducted by Roessler et al. [6], no fewer than six items related to implementation of the ADA and the Family and Medical Leave Act (FMLA) were reported among the 12 most prominent employment-related problems identified by Americans with MS. Specifically, the majority of respondents reported having been treated unfairly in the hiring process by employers (73\%), having been denied reasonable accommodations (58\%), having received lower pay compared to their peers who are without disabilities (53\%), being refused schedule modifications that would have enabled them to continue working (59\%), having received inadequate health insurance coverage (73\%), and having received little or no information about their legal rights from employers (69\%).

Between 1992 and 2003, the United States Equal Employment Opportunity Commission (EEOC) received and resolved 3,669 allegations of employment discrimination from people with MS under Title I of the ADA [36]. Allegations of unlawful termination constituted the most commonly cited form of workplace discrimination $(29.9 \%$ ), followed in descending order by complaints related to reasonable accommodations (21.9\%), terms and conditions of employment (9.8\%), harassment $(6.7 \%)$, hiring (3.8\%), discipline (3.4\%), constructive discharge (i.e., creating a work environment that makes it impossible for the person to continue working; $3.0 \%)$, layoff (2.8\%), and promotion (2.5\%). People with MS filing ADA Title I allegations were mostly female $(66.5 \%)$, predominantly Caucasian (76.1\%), and of mid-career age on average $(M=42.47$ years, $S D=8.54)$. Allegations were most often filed against employers in the South United States Census tracking region (35.7\%), and employers in the service, financial, insurance, and real estate industries were most often the subjects of ADA Title I complaints.

In comparison to ADA Title I complainants with other disabilities, people with MS were more likely than people with other disabilities to allege discrimination under Title I of the ADA in the areas of reasonable accommodations, terms and conditions of employment, constructive discharge, and demotion; less likely to allege discrimination in the area of hiring; and more likely to have their allegations of discrimination resolved in their favor by the EEOC [37].

Contextual factors outside of the workplace also have an impact on the careers of adults with MS. For example, it is well documented that people with MS who receive disability benefits from private insurers or from government agencies face extreme difficulties in restarting their careers. Indeed, the benefits paid by most long-term disability insurance carriers and the Social Security Administration's two disability programs (i.e., Social Security Disability Insurance [SSDI] and Supplemental Security Income [SSI]) are predicated on the beneficiary being too disabled to work [38]. This requirement provides a powerful systemic disincentive that keeps thousands of Americans with MS from participating in the labor force. Once they have been adjudicated as too severely disabled to work by either long-term disability insurers or Social Security (or sometimes both), they integrate the external confirmation of their disabled status into their own self-concepts - self-concepts that do not necessarily include the role of worker [39]. From that point on in the vast majority of cases, unemployment and receipt of disability benefits conjoin in a self-fulfilling prophecy for people with MS. According to Fraser et al. [40], people with MS progress from active employment to short-term disability insurance, long-term disability insurance, and, finally, SSDI at higher and faster rates than people with most other disabilities. This is especially problematic given the estimate that less than one percent of Americans with MS who receive SSDI benefits will ever resume gainful employment $[13,22]$.

\subsection{Focus of the study}

Although a considerable body of research has been devoted in recent years to the factors associated with labor force participation among people with MS and the difficulties that people with MS have as they attempt to maintain their careers, less attention has been accorded specific mutable employment concerns from the perspectives of Americans with MS. Indeed, since Roessler et al. [6] completed the most recent broadbased national investigation of employment strengths and weaknesses from the point of view of Americans with MS, several changes in Federal legislation and the general economy seem to warrant a current examination of the most important employment-related issues facing people with MS.

The Americans with Disabilities Act Amendments Act of 2008, for example, expanded the definition of disability to cover many Americans who were not considered people with disabilities prior to the Amendments. In fact, people with MS are now presumptively considered people with disabilities under the Amendments [27]. The Affordable Care Act provides health insurance coverage for Americans with pre-existing conditions and removes annual and lifetime caps on 
health insurance coverage, thereby protecting many people with MS whose coverage may have been less comprehensive prior to enactment of the law [41]. The Great Recession of 2007-2010 compressed the American labor force and reduced employment opportunities for people with and without disabilities throughout the nation.

Now, more than 10 years since Roessler et al. [6] examined the employment concerns of Americans with $\mathrm{MS}$, it is time for a new look at how recent policy and economic trends may have affected the perceptions of people with MS regarding the world of work. Accordingly, the purpose of this article is to present descriptive findings from a stratified random sample of 1,924 people with MS who took part in a national survey utilizing Participatory Action Research (PAR) [42] techniques. Findings from the study provide a contemporaneous view of strengths and weaknesses in employment policies and practices and, thus, of the priorities for employment agenda planning so that more individuals with MS can remain in and return to the workforce.

The research questions for this investigation were as follows:

1. What are the most important employment concerns from the perspectives of Americans with MS?

2. What are the important employment concerns with which Americans with MS are most satisfied (i.e., what are the strengths in employment policies and practices affecting people with MS)?

3. What are the important employment concerns with which Americans with MS are least satisfied (i.e., what are the weaknesses in employment policies and practices affecting people with MS)?

\section{Method}

The authors implemented a Participatory Action Research (PAR) methodology to survey the employment concerns of people with MS. National Multiple Sclerosis Society (NMSS) chapters throughout the United States participated in various phases of the study, beginning with survey construction and ending with responding to the survey in paper-and-pencil, online, or telephone administrations. Thus, the survey itself and the resulting profile of employment strengths and weaknesses are thoroughly grounded in the perspectives of people with MS

\subsection{Participants}

The total respondent sample consisted of 1,924 members of nine NMSS chapters across the United States, 410 men $(21.3 \%)$ and 1,514 women $(78.7 \%)$. Fiftythree percent $(53 \%)$ of respondents described their communities as suburban, whereas 24.9 percent lived in urban areas and 22.1 percent resided in rural settings. With a mean age of 53.94 years $(\mathrm{SD}=12.20$ years), most of the respondents were Caucasian $(75.6 \%)$, although the oversampling procedure described later in this Method section resulted in higher proportions of Hispanic/Latino (10.7\%) and African American $(11.2 \%)$ respondents than are typically reported in studies of people with MS. Less than one percent of the sample identified their racial or ethnic background as Asian or Pacific Islander (0.6\%) or Native American or Alaskan Native (0.5\%).

Less than 40 percent $(39.6 \%)$ of respondents were employed for pay at the time of the survey, even though the group was an experienced (98\% had employment histories and $82 \%$ were still working at the time of diagnosis) and well-educated group of workers (98\% were high school graduates and $46 \%$ were college graduates). Nearly two-thirds of the sample were dealing with the relapsing-remitting form of MS (64.7\%), and the mean number of MS symptoms reported was 7.65 $(\mathrm{SD}=3.87)$. In descending order of frequency, the most commonly reported symptoms were fatigue (reported by $79.1 \%$ of the sample), balance/coordination problems $(64.6 \%)$, diminished physical capability (62.2\%), gait/mobility problems $(56.1 \%)$, tingling in the extremities $(51.8 \%)$, bowel/bladder dysfunction $(50.1 \%)$, numbness (49.5\%), cognitive impairment (49.2\%), spasticity $(43.5 \%)$, pain (42\%), sleep disturbance (37.5\%), depression (34.7\%), vision problems (33\%), anxiety (28.4\%), sexual dysfunction (26.4\%), speech problems $(16 \%)$, tremor $(16 \%)$, and bipolar disorder $(3 \%)$.

\subsection{Instrument}

The instrument used in the survey was a 98 -item questionnaire that included fixed and open response sets. Components of the survey used in this investigation included sections on participant demographics, illness-related variables, and 38 employment concerns items. The 38 employment concerns items were the primary focus of this study. In responding to those items, unemployed and employed individuals indicated whether they considered the concern to be important 
and whether they were satisfied that the concern was being addressed in their communities. For example, in responding to the item regarding health insurance coverage, respondents were asked, "Is it important that people with MS have adequate health insurance coverage?" and "Are you satisfied that people with MS have adequate health insurance coverage?" Other concerns items addressed such issues as access to information on disability benefits programs, discrimination in hiring and retention practices of employers, employment protections under major legislation, the quality of rehabilitation and employment services, access to assistive technology, and support for returning to work and planning for the future.

\subsection{Procedures}

In developing the employment concerns section of the survey, the authors consulted with 13 people with MS who were members of one NMSS chapter in the Midwestern United States. In a three-hour working group session, these consumers reviewed a pool of 157 employment practice and policy-related items to select the 38 they considered most relevant to people with MS. Working group members were also encouraged to nominate additional items for the survey, but the group reported that the items in the pool, with minor editing, adequately covered their concerns.

After preparing the survey based on the input of people with MS, the researchers asked a panel of MS experts to review the instrument for readability and content coverage. Following final revisions of the questionnaire, the researchers identified, with the assistance of the NMSS, nine chapters to participate in the study. These chapters were selected because they provided a strong representation of geographic areas, rural/urban/suburban settings, and diverse racial/ethnic groups.

The original target sample for this investigation included 8,000 people with MS representing the 9 chapters. As a means of ensuring adequate representation of Hispanic/Latino and African-American respondents, the researchers oversampled members of those two groups within NMSS chapters that had relatively high proportions of Hispanic/Latinos and African-Americans on their client registries. Eight of the participating NMSS chapters were asked to identify stratified random sub-samples of 800 clients (stratified by racial/ethnic backgrounds depending upon the representation of Hispanic/Latinos and African Americans in their client registries), and one chapter was asked to draw a stratified random sub-sample of 1,600 clients - 100 African Americans, 800 Hispanic/Latinos, and 700 clients from other racial and ethnic backgrounds. The goal of this sampling procedure was to ensure that at least five percent of the overall respondent sample was Hispanic/Latino and that at least five percent was African American; these proportions are consistent with commonly held estimates of population parameters for people with MS [43].

Within the stratified random target sample of 8,000 people with MS, 1,123 (14\%) were Hispanic/Latino and 603 (7.5\%) were African American. The remaining 6,274 members of the target sample represented all other racial and ethnic backgrounds in the NMSS' client data tracking system.

Once the sampling plan was finalized, the authors prepared the survey for distribution by each of the chapters. Two weeks prior to mailing the survey, chapter service directors sent a pre-notice letter [44] to those selected for the national survey $(N=8,000)$. The prenotice letter explained the purpose of the study and the importance of completing and returning the survey. The survey was then mailed with another explanatory cover letter from the project director. The cover letter provided instructions for completing the questionnaire in hard copy, online, or via telephone depending upon the preferences of the respondent. Four weeks after the survey had been mailed; the authors provided the chapters with "reminder/thank you" postcards [44] to send to the 8,000 people who received the questionnaire. In a final effort to increase survey return rates, participating NMSS chapters sent an e-mail "blast" to the target sample six weeks after the reminder/thank you postcards had been delivered.

Six hundred thirty-one surveys were returned to participating chapters as undeliverable, reducing the available target sample to 7,369 people with MS. Of the available target sample, 1,924 members returned questionnaires, resulting in a response rate of $26 \%$.

\subsection{Data analysis}

Descriptive statistics such as frequencies and percentages were used to answer the three research questions. For each of the 38 employment concerns items, an Importance rating was calculated as the percentage of respondents who evaluated the item as important. Likewise, each item was also assigned a Satisfaction rating that was calculated as the percentage of respondents who were satisfied with the current status of that item. An employment strength was defined 
as an item with a high Importance rating (i.e., greater than 50 percent) and a high Satisfaction rating (i.e., greater than 50 percent). An employment weakness was defined as an item with a high Importance rating and a low Satisfaction rating (i.e., less than 50 percent). This simple-majority standard for considering items either strengths or weaknesses was used for ease of interpretation, consistent with previous concerns report research.

\section{Results}

The first research question addresses the importance ratings that respondents assigned to each item. Support for the PAR approach to instrument development whereby a working group of people with MS helped researchers to identify the 38 employment concerns items is evident in the fact that all 38 items were evaluated as important by at least two-thirds of the sample, and 37 out of the 38 items had importance ratings of at least 80 percent. Table 1 lists the 38 employment concerns items in descending order of importance ratings.

The second research question addresses the perceived strengths in employment policies and practices from the vantage point of people with MS. Defining a strength as an item with an importance rating of at least 50 percent and a satisfaction rating of at least 50 percent, the researchers identified a total of 32 strengths. Table 2 presents these strength items in descending order of their satisfaction ratings.

Table 1

Employment Concerns Items and Their Importance Ratings

\begin{tabular}{|c|c|}
\hline Item & $\%$ Importan \\
\hline \multicolumn{2}{|l|}{ People with MS... } \\
\hline Are provided the same retirement benefits as other workers & 97.5 \\
\hline Have adequate health insurance coverage & 97.2 \\
\hline Have access to health insurance when changing jobs or returning to a previous job & 97.0 \\
\hline Have adequate information about benefits such as health and disability (short and long-term) insurance & 96.9 \\
\hline Are made aware of employer expectations in the same way as other employees & 96.9 \\
\hline Receive the same on-the-job training opportunities as other workers & 96.8 \\
\hline Are evaluated based on their performance, not on assumptions about MS & 96.7 \\
\hline Have the same opportunity for promotion as other workers & 96.6 \\
\hline Are encouraged to take control of their lives & 96.5 \\
\hline Have access to adequate information about Social Security programs & 96.5 \\
\hline Know what to do if they encounter discrimination at work & 96.5 \\
\hline Understand the benefits of disclosing disability status to employers & 96.4 \\
\hline Have their seniority honored in the same way as other employees & 96.3 \\
\hline Can expect employers to respect their privacy regarding health and disability-related information & 96.3 \\
\hline Make the decision to quit or retire without being pressure or forced to do so by their employers & 96.3 \\
\hline Are not subjected to harassment or intimidation in the workplace because of their MS & 96.2 \\
\hline Are treated fairly in termination or demotion decisions made by their employers & 95.9 \\
\hline Receive the same severance pay as other workers & 95.7 \\
\hline Are recalled from layoffs in the same manner as other workers & 95.7 \\
\hline Have access to service providers who understand the needs of people with MS & 95.6 \\
\hline Understand the employment protections of Title I in the Americans with Disabilities Act as Amended (ADA) & 95.2 \\
\hline Have physical access to workplace facilities & 95.1 \\
\hline Have the same maternity and family leave options as other workers & 94.8 \\
\hline Understand the health insurance provisions and protections of the Affordable Care Act (i.e., Obamacare) & 94.4 \\
\hline Are treated fairly by employers in the hiring process & 93.9 \\
\hline Know their right regarding job-related physical examinations & 93.6 \\
\hline Can request a review of their accommodation needs without fear of retaliation & 93.6 \\
\hline Can expect employers to respond to their accommodation needs in a timely manner & 93.2 \\
\hline Know how to discuss their job accommodation needs with employers & 93.0 \\
\hline Have access to assistive technology resources needed for work & 92.9 \\
\hline Have access to the full range of employment opportunities offered by their employers & 92.6 \\
\hline Have their qualifications for employment and advancement fairly evaluated by employers & 92.3 \\
\hline Are considered for other jobs in the same company if their MS prevents them from returning to their former jobs & 92.2 \\
\hline Are evaluated no more frequently than other workers & 92.2 \\
\hline Are given references from past employers based on work performance, not on disability status & 91.2 \\
\hline Have opportunities for job training or retraining & 89.6 \\
\hline Are asked interview questions related to job tasks and personal qualifications rather than to health and disability matters & 84.4 \\
\hline Are expected, by their physicians and significant others, to remain employed after diagnosis & 67.7 \\
\hline
\end{tabular}


Table 2

Employment Strengths

\begin{tabular}{|c|c|}
\hline Item & $\%$ Satisfied \\
\hline \multicolumn{2}{|l|}{ People with MS... } \\
\hline Are encouraged to take control of their lives & 80.2 \\
\hline Have the same maternity and family leave options as other workers & 77.4 \\
\hline Are provided the same retirement benefits as other workers & 76.6 \\
\hline Are made aware of employer expectations in the same way as other employees & 71.9 \\
\hline Receive the same severance pay as other workers & 71.0 \\
\hline Receive the same on-the-job training opportunities as other workers & 70.7 \\
\hline Have their seniority honored in the same way as other employees & 69.9 \\
\hline Are given references from past employers based on work performance, not on disability status & 67.8 \\
\hline Have physical access to workplace facilities & 65.7 \\
\hline Are evaluated no more frequently than other workers & 65.5 \\
\hline Have access to service providers who understand the needs of people with MS & 64.1 \\
\hline Are not subjected to harassment or intimidation in the workplace because of their MS & 63.2 \\
\hline Can expect employers to respect their privacy regarding health and disability-related information & 62.5 \\
\hline Are expected, by their physicians and significant others, to remain employed after diagnosis & 61.2 \\
\hline Are asked interview questions related to job tasks and personal qualifications rather than to health and disability matters & 61.0 \\
\hline Have their qualifications for employment and advancement fairly evaluated by employers & 61.0 \\
\hline Have access to adequate information about Social Security programs & 59.9 \\
\hline Have opportunities for job training or retraining & 58.8 \\
\hline Have access to health insurance when changing jobs or returning to a previous job & 58.8 \\
\hline Have adequate health insurance coverage & 58.6 \\
\hline Are treated fairly by employers in the hiring process & 57.4 \\
\hline Have adequate information about benefits such as health and disability (short and long-term) insurance & 57.1 \\
\hline Are treated fairly in termination or demotion decisions made by their employers & 56.0 \\
\hline Are evaluated based on their performance, not on assumptions about MS & 55.9 \\
\hline Have access to assistive technology resources needed for work & 54.9 \\
\hline Are recalled from layoffs in the same manner as other workers & 54.8 \\
\hline Have the same opportunity for promotion as other workers & 54.6 \\
\hline Make the decision to quit or retire without being pressure or forced to do so by their employers & 54.3 \\
\hline Know their right regarding job-related physical examinations & 53.9 \\
\hline Can expect employers to respond to their accommodation needs in a timely manner & 52.1 \\
\hline Have access to the full range of employment opportunities offered by their employers & 51.5 \\
\hline Know what to do if they encounter discrimination at work & 50.6 \\
\hline
\end{tabular}

The third research question addresses perceived employment weaknesses from the point of view of survey respondents. The researchers defined a weakness as an item with an importance rating of at least 50 percent and a dissatisfaction rating of at least 50 percent. By that definition, six employment concerns items qualify as weaknesses. Table 3 presents the six weakness items in descending order of their dissatisfaction ratings.

\section{Discussion}

The first observation that should be made about the 38 employment concerns items considered in this study is that all 38 were evaluated as important by at least two-thirds of the sample - and 37 of the 38 were evaluated as important by at least 80 percent of the sample. This result is supportive of the PAR approach to instrument development whereby 13 members of the NMSS identified the 38 highest-priority employment issues facing Americans with MS.

Given the fact that all 38 employment concerns were judged to be important, all items in the study were classified as either strengths or weaknesses. With 32 strength items being rated as satisfactory by the majority of respondents and only 6 weakness items being rated as unsatisfactory by the majority of respondents, the employment picture for Americans with MS appears promising at first glance. However, less than 40 percent of respondents were employed at the time of the survey, which indicates a strong need for improvements in the policies and services designed to help people with MS and other disabling conditions enter, re-enter, or stay in the workforce. It should also be noted that half of the 32 items that met the criteria for employment strengths were sources of satisfaction for a slight majority of the sample; 16 strength items had satisfaction ratings between 50 and 60 percent. 
Table 3

Employment Weaknesses

Item

People with MS...

Understand the health insurance provisions and protections of the Affordable Care Act (i.e., Obamacare)

Know how to discuss their job accommodation needs with employers

Can request a review of their accommodation needs without fear of retaliation

Understand the employment protections of Title I in the Americans with Disabilities Act as Amended (ADA)

Are considered for other jobs in the same company if their MS prevents them from returning to their former jobs

Understand the benefits of disclosing disability status to employers

$\%$ Dissatisfied

53.4

53.0

52.7

51.7

51.2

50.6

\subsection{Employment strengths}

For purposes of discussion, we have divided the 32 employment strengths into High Strength and Moderate Strength subcategories. High strength items are those with satisfaction ratings of greater than 60 percent, whereas moderate strength items are those with satisfaction ratings between 50 and 60 percent. Discussion focuses on ways to preserve the high strength items and preserve and, in some cases, enhance the moderate strength items.

\subsubsection{High strengths}

The most prominent employment strengths for people with MS cluster into themes such as personal control and expectations of others, employee benefits, communication with employers, equitable workplace policies and fair treatment, physical accessibility of the work place, performance evaluation, and access to service providers. Compared to findings from the 2002 Roessler et al. survey, which predated the ADA Amendments Act, the Affordable Care Act, and the Great Recession, these high strength themes suggest significant progress in the optimism that people with MS hold for their future employment prospects. These findings indicate that perceptions of people with MS regarding the cooperativeness of employers, access to service providers, and the independence with which employment and other life decisions are made have improved considerably since the turn of the 21 st Century. So, too, are improvements evident in the perceived fairness of personnel policies, in employee benefits, and in the physical accessibility of the workplace.

The fact that these improvements in the perceptions of people with MS regarding their employment situations have not translated into improvements in the rate of labor force participation underscores what a durable and deeply entrenched phenomenon unemployment is as an accompaniment of MS. Undoubtedly, factors such as disincentives in disability benefits programs
[38], the combined effects of cognitive and mobility impairments [24], and more subtle forms of workplace discrimination [36] are more potent impediments to employment than these perceived strengths are facilitators of job retention and return to work.

Still, the overall employment picture for people with MS is likely to improve over time if continued progress is realized in (a) the access that people with MS have to service providers, (b) their communication with employers, (c) the control and independence that people with MS assert in their lives, and (d) the attitudinal and physical work environment. The state-Federal vocational Rehabilitation (VR) program, which has historically underserved people with MS, could contribute to this ongoing progress through redoubled outreach and consultation efforts aimed at people with MS. Nissen and Rumrill [45] called upon VR counselors to increase job retention and post-employment services for people with MS who are currently employed but who are at risk of losing their jobs. Bishop et al. [12] underscored the importance of helping people with MS procure assistive technology and access transportation as a means of enhancing community and labor force participation. Fraser et al. [24] exhorted rehabilitation professionals to interface with both health care providers and employers in providing employment assistance to people with MS. These strategies would help to preserve the high strength items identified by respondents in the present study.

\subsubsection{Moderate strengths}

The 16 moderate-strength items cluster into themes such as Social Security and other disability benefits, training and advancement opportunities, health insurance coverage, hiring and promotion policies, access to technology, layoff and termination, and civil rights and workplace discrimination. Here, the need for accurate information, focused advocacy efforts, and direct services concerning these critically important employment issues is clear. 
Specifically, to move these moderate-strength items into the high-strength designation, people with MS need up-to-date and easily understandable information about Social Security disability programs, employer-based short and long-term disability insurance benefits, and private or employer-based health insurance benefits. They also need to understand employer policies regarding discipline, layoff, and termination, not to mention what to do if they experience those actions in a manner that is unfair or unlawful.

Information about the 2008 ADA Amendments Act will help people with MS understand their civil rights to fair treatment in the workplace [46]. This law is discussed in greater detail in subsequent paragraphs, and rehabilitation professionals can play an important role in educating people with MS about changes to the ADA that hold significant promise for people with MS. Likewise, accessible information concerning the Affordable Care Act, which was the most prominent weakness identified by respondents in this study, could enhance awareness of health insurance benefits and protections among people with MS, thereby preserving and bolstering the moderate strength associated with health insurance coverage in general.

Finally, the employment situation for people with MS could be enhanced if services and supports related to on-the-job training and promotion or advancement could be improved. Consultation for people with MS regarding their next career steps helps solidify their identities as productive workers, which is especially important given that the onset and progression of MS often require them to reconsider their vocational identities [45]. Maintaining their identities as productive workers makes people with MS less vulnerable to self-perceptions that focus on declining health, dependency, and lack of employment potential [39], and it enables them to enjoy longer and greater access to the well-documented health and lifestyle benefits of paid employment [7, 24, 47].

\subsection{Employment weaknesses}

The six employment weaknesses, which were sources of dissatisfaction for at least 50 percent of respondents, cluster into four themes: understanding the Affordable Care Act, on-the-job accommodations and Title I of the ADA, reassignment as a job retention strategy, and disclosure of disability. Discussion focuses on strategies for ameliorating these weaknesses as a means of increasing the rate of labor force participation among people with MS.

\subsubsection{Understanding the affordable care act}

For adults with chronic illnesses such as MS, the Affordable Care Act of 2012 represents comprehensive and critical legislation protecting their right to health insurance and medical treatment [41]. The Affordable Care Act provides access to low-cost insurance coverage to people who are uninsured and requires employers to provide group health insurance coverage for employees who work at least 30 hours per week, the latter provision being especially important for people with MS who may need to reduce their hours at work due to changes in their health status [45]. This law also prohibits health insurance companies from excluding people from coverage based on pre-existing conditions in a more comprehensive manner than was previously set forth in the Health Insurance Portability and Accountability Act [41]. Needless to say, people with MS and other chronic illnesses will benefit greatly from the elimination of pre-existing condition exclusions, which were identified as a major employment weakness in the only other national survey of employment strengths and weaknesses among people with MS [6]. Furthermore, the Affordable Care Act prohibits health insurance companies from imposing annual or lifetime "caps" on coverage, a provision that will benefit people with MS as their life expectancies continue to increase at rates similar to those of the general public; no longer must people with MS worry about exhausting their health insurance coverage as they experience age-related changes in their health status.

Given the fact that the item regarding the Affordable Care Act was the greatest source of dissatisfaction among all 38 items in this employment concerns survey, it is imperative that people with MS have access to clear and understandable information about the important protections available to them through this legislation. Advocacy and direct service efforts to help people with MS understand their health insurance options and access quality health care are an important adjunct to state Vocational Rehabilitation and other employmentrelated services for people with MS. Physicians, social workers, nurses, counselors, and rehabilitation professionals alike must be well versed in the provisions of the Affordable Care Act, and they must make concerted efforts to communicate those provisions to adults with MS if the most prominent weakness reported by respondents in this study is to be ameliorated. All 
working Americans dealing with MS should understand that employers are required to provide health insurance coverage to full-time workers, that adults with MS cannot be denied coverage due to the presence of a pre-existing condition, and that adults with MS do not face any type of lifetime "cap" to their coverage.

\subsubsection{On-the-job accommodations and Title I of the ADA}

Three of the employment weaknesses pertained to deficiencies that respondents experienced regarding how to initiate a discussion of their need for an accommodation, how to review accommodation options without invoking employer resistance (i.e., retaliation), and how to carry out the entire process within the protections of the ADA. All three of these weaknesses are closely connected in terms of subject matter, with the best beginning place being an understanding of the important changes regarding on-the-job accommodations present in the ADA Amendments Act (ADAAA)).

Prior to the ADAAA, people with disabilities first had to achieve the designation of "person with a disability," which was no easy task given concepts in the legislation such as "substantial limitation" and "mitigating measures." Put simply, an individual with MS might not qualify for protected class status under the ADA (i.e., person with a disability) if his or her MS was episodic and not substantially limiting at certain times or if the effects of the MS were controllable with medication or other medical aids (i.e., mitigating measures).

Thanks to the work of disability advocates, Congress implemented the ADAAA on January 1, 2009 with specific provisions that strengthen the position of people with MS in their efforts to present their accommodation needs to their employers and to discuss their options without retaliation from the employer. First, the ADAAA simplified the process of qualifying for protections accorded a person with a disability by specifying that some impairments are automatically considered disabilities without a test of "substantial limitation" (e.g., multiple sclerosis, deafness, blindness, diabetes, epilepsy, cancer, psychiatric disorders, muscular dystrophy, HIV and AIDS to name a few). Similarly, conditions considered to be in remission such as MS or cancer, often through mitigating measures (e.g., medication or medical aids), are considered disabilities if they would substantially limit the person in life activities when active or without the benefits of mitigating measures. Rather than disability determination, the ADAAA placed greater emphasis on determining whether discrimination occurred and whether the employer made adequate efforts to reasonably accommodate [46].

In relation to initiating a request for an accommodation, people with MS need to know that they have easier access to ADA protections to guard against retaliation from the employer. Employees with MS should find reassurance in two implications of the legislation. As previously noted, the impetus in the ADAAA is on successful accommodation and job retention, not on disability determination. Second, the implicit assumption in the ADAAA is that failure to reach agreement on an accommodation may stem from a lack of good faith on the part of the employer rather than intransigence on the part of the employee. However, simply understanding and invoking, if necessary, one's rights under the ADA does not obviate the need for the employee with MS to approach the process in a thoughtful and skillful way.

Following a prescribed process for requesting an accommodation or reviewing accommodation options can potentially reduce the possibility of retaliation on the employer's part. In their Win-Win brochure available from the NMSS, Roessler and Rumrill [48] recommend that employees initiate an informal and friendly dialogue with their employers without mentioning the ADA. The thoughtful part of the process presumes that the employee with MS has identified the problem that he or she is having and the range of available accommodations to reduce or remove those problems. Helpful advice is available from the nearest chapter of the National MS Society, the Job Accommodation Network (AskJan.org, 800-526-7234 (voice), 877-781-9403 (TTY), and the state vocational rehabilitation office. Julian et al. [10], Uccelli et al. [5], and Krause et al. [14], listed a variety of accommodations worthy of consideration such as flexibility in work hours, regularly scheduled breaks, ergonomic job modifications to address dexterity or mobility limitations, improved workplace accessibility, and compensatory techniques for coping with cognitive limitations in attention and information processing.

The skillful approach to requesting an accommodation involves preparation. In preparing to request a review of one's accommodation needs, the employee with MS should generate a written list of accommodations and then analyze each as to how it would increase the person's productivity and how the employer or supervisor would respond. Important questions from the employer's perspective include whether the accom- 
modation would be cost effective and how it might alter the nature of the business. In a job interview, the applicant with MS is not required to request an accommodation prior to being offered the job. Whether the accommodation request is during the job interview or following tenure on the job, the worker with MS is not required to reveal his or her diagnosis but may be asked for documentation from a physician.

\subsubsection{Reassignment as a job retention strategy}

Given that reassignment to another position within the same company or organization is viewed in ADA title I regulations as a last resort after all other accommodation strategies have proven unfruitful [45], it is not surprising that this issue is a major source of concern for people with MS. Rumrill et al. [27] reported that reassignment was one of the least frequently implemented workplace accommodations for people with MS, and requesting reassignment was met with more employer resistance than any other accommodation option identified by workers with MS. Accordingly, rehabilitation professionals seeking to help people with MS retain employment must work closely with employees and employers to consider and evaluate all other possible accommodations before a reassignment is contemplated. Then, if all other accommodation options are exhausted and the worker is reassigned to another position, support must be provided to help the worker adjust to his or her new job, including any accommodations that would aid in the performance of job tasks. If the employer is unionized, it may be necessary to consult the collective bargaining agreement for rules regarding seniority and other criteria that are considered in making reassignment decisions.

\subsubsection{Disclosure of disability}

The benefit of disclosure of disability is that it places the individual under the protections of the ADA. The drawback of disclosure is that it, in some cases, may result in stigmatizing the employee with a disability. Of course, the protections provided by the ADA address nondiscrimination in the workplace generally and provision of reasonable accommodations specifically [48]. The ADA mandates that an individual with a disability cannot be fired from a position if he or she is able to perform the essential functions of the position with or without reasonable accommodation. If an accommodation is needed, the individual should follow the previously discussed thoughtful and skillful request strategy to minimize negative reactions. The proper accommodation should enable the individual to per- form the essential functions of the position and resume acceptable levels of productivity, and Simmons et al. [49] stressed the importance of "gradual accommodation of emergent symptoms in the workplace" (p. 934) as an effective job retention strategy. However, applicants or incumbents are under no obligation to disclose the presence of disability if they do not need an accommodation.

The issue with disclosure of disability is that it represents an acknowledgement that the employee is no longer able to perform job duties without accommodation. For this reason, Vickers [1, p. 194] recommended that employees with MS "wait to disclose until you have proven yourself to your employer." While that recommendation may apply in some situations, it also allows small problems to become large ones, thereby threatening the person's job security [49].

As Vickers found, disclosure can expose the person to stigma associated with disability, giving rise to negative expectations on the part of some employers. Respondents with MS in Vickers' qualitative study believed that disclosure caused some employers to view them as unable to return to their prior levels of productivity. In some cases, employers anticipated that the employees with disabilities would no longer be able to make money for them and that this first request was only the beginning of the adjustments the employee would seek, thereby increasing the costs of retaining the individual and the envy of nondisabled workers who might request similar changes in their jobs. It is at this point that the nondiscrimination provisions of the ADAAA and the advocacy of the Equal Employment Opportunity Commission are critical if evidence of discrimination occurs, e.g., use of differential and unfair standards of evaluation, increased demands for productivity, overbearing and more frequent supervisory oversight, bullying by co-workers, and requests to assume additional and inappropriate responsibilities [1]. In their focus group study, Sweetland, Riazi, Cano, and Playford [50] reported that adults with MS requested more assistance from advocates (e.g., a work specialist therapist) at this complex stage who could both intervene with the employer and educate employees with MS about discrimination legislation and legal protections.

\subsection{Limitations}

The present study had several limitations that should be kept in mind when interpreting results. These 
included the complete reliance on self-report data, the low survey return rate and associated threats to external validity, and the restricted range of responses to the 38 employment concerns items that resulted from the dichotomous, yes/no scaling of importance and satisfaction ratings. Readers should also note that findings from this study of Americans with MS may not generalize to people with MS in other countries due to international differences in the policies and practices that govern healthcare, human services, and workforce development.

\section{Conclusion}

The purpose of this article was to describe the highest priority strengths and weaknesses in existing employment policies and services as identified by a large, stratified national sample of Americans with MS $(N=1,924)$. A total of 38 employment concerns were considered in this investigation, 32 of which met the criteria for employment strengths and six of which were employment weaknesses. Still, only 39.6 percent of the respondent sample was employed at the time of the survey, which underscores the need for continued improvements in the services and supports that assist people with MS in maintaining or resuming their careers following diagnosis with this highly intrusive disease.

By understanding the most prominent employment concerns of people with MS, as well as intervention and systems change strategies that address those issues, rehabilitation and health professionals can help society capitalize on the considerable talents and expertise of people with MS. These experienced, well-educated, and productive workers can continue to make important contributions to the American work force, but only if vocational rehabilitation interventions and American disability policies are grounded in their expressed perspectives.

\section{Acknowledgments}

This research was funded through a Health Care Delivery and Policy Research grant from the National Multiple Sclerosis Society, New York, NY. The authors wish to thank the National Multiple Sclerosis Society, its participating chapters, and the study participants for their support and assistance with this research.

\section{References}

[1] Vickers M. Antenarratives to inform health care research: Exploring workplace illness disclosure for people with multiple sclerosis (MS). Journal of Health and Human Services Administration 2012;35:170-206.

[2] Antao L, Shaw L, Ollson K, Reen K, To F, Bossers A, Cooper L. Chronic pain in episodic illness and its influence in work occupations. Work: A Journal of Prevention, Assessment, and Rehabilitation 2013;44:11-36.

[3] Johnson K, Amtmann D, Klasner E, Kuehn C. Medical, psychological, social and programmatic barriers to employment for people with multiple sclerosis. Journal of Rehabilitation 2004;70(1):38-49.

[4] VanDenand T. Employment needs of people with multiple sclerosis: A review of current literature and application to occupational therapy practice. Occupational Therapy in Health Care 2006;20(1):61-77.

[5] Uccelli M, Specchia C, Battaglia M, Miller D. Factors that influence the employment status of people with multiple sclerosis: A multi-national study. Journal of Neurology 2009;256:1989-96.

[6] Roessler R, Rumrill P, Hennessey M. Employment concerns of people with multiple sclerosis: Building a national employment agenda. Kent, OH: Kent State University Center for Disability Studies, Report Submitted to the National Multiple Sclerosis Society, 2002.

[7] Sumner G. Project Alliance: A job retention program for employees with chronic illnesses and their employers. New York: National Multiple Sclerosis Society, 1997.

[8] Rumrill P. Help to stay at work: Vocational rehabilitation strategies for people with multiple sclerosis. Multiple Sclerosis in Focus 2006;7:14-8.

[9] Moore P, Harding K, Clarkson H, Pickersgill T, Wardle M, Robertson N. Demographics and clinical factors associated with changes in employment in multiple sclerosis. Multiple Sclerosis Journal 2013;19:1647-54.

[10] Julian L, Vella L, Vollment T, Hadjimichael O, Mohr D. Employment in multiple sclerosis: Exiting and reentering the work force. Journal of Neurology 2008;255:1354-60.

[11] Chiu C, Chan F, Bishop M, DaSilva Cardosa E, O’Neill J. State vocational rehabilitation services and employment in multiple sclerosis. Multiple Sclerosis Journal 2013;19:1655-64.

[12] Bishop M, Roessler R, Rumrill P, Frain M, Waletich B, Umeasiegbu B. The relationship between housing accessibility variables and employment status among adults with multiple sclerosis. Journal of Rehabilitation 2013;79(4):4-14.

[13] DeLuca J, Nocentini U. Neuropsychological, medical, and rehabilitative management of persons with multiple sclerosis. Neurorehabilitation 2011;29:197-219.

[14] Krause I, Kern S, Horntrich A, Ziemssen T. Employment status in multiple sclerosis: Impact of disease-specific and non-disease specific factors. Multiple Sclerosis Journal 2013;19:1792-9.

[15] Krakavcova M, Nagyova I, Van Dijk J, Rosenberger J, Gavelova M, Middel B, Szilasiova J, Gdovinova Z, Groothoff J. Self-rated health and employment status in patients with multiple sclerosis. Disability and Rehabilitation 2010;32:1742-8.

[16] Strober L, Christodoulou C, Benedict R, Westervelt H, Melville P, Scherl W, Weinstock-Grittman B, Rizvi S, Goodman A, Krupp L. Unemployment in multiple sclerosis: The contribution of personality and disease. Multiple Sclerosis Journal 2012;18:647-53. 
[17] Smith M, Arnett P. Factors related to employment status changes in individuals with multiple sclerosis. Multiple Sclerosis 2005;11:602-9.

[18] Rumrill P, Hennessey M, Nissen S. Employment issues and multiple sclerosis (2nd Edition). New York: Demos, 2008.

[19] Roessler R, Rumrill P, Fitzgerald S. Predictors of employment status for persons with multiple sclerosis. Rehabilitation Counseling Bulletin 2004;47:96-103.

[20] Smith M, Arnett P. Factors related to employment status changes in individuals with multiple sclerosis. Multiple Sclerosis 2005;11:602-9.

[21] Moore P, Harding K, Clarkson H, Pickersgill T, Wardle M, Robertson N. Demographics and clinical factors associated with changes in employment in multiple sclerosis. Multiple Sclerosis Journal 2013;19:1647-54.

[22] Fraser R, Clemmons D, Bennett F. Multiple sclerosis: Psychosocial and interventions. New York: Demos, 2002.

[23] Edgley K, Sullivan M, Dehoux E. A survey of multiple sclerosis, part 2: Determinants of employment status. Canadian Journal of Rehabilitation 1991;4(3):127-32.

[24] Fraser RT, Kraft GH, Ehde DM, Johnson KL. The MS workbook: Living fully with multiple sclerosis. Oakland, CA: New Harbinger Publications, Inc., 2006.

[25] Kalb R. Multiple sclerosis: The questions you have, the answers you need. New York, NY: Demos Medical Publishing, Inc., 2012.

[26] McReynolds C, Koch L. Psychological issues. In P. Rumrill and M. Hennessey (Eds.). Multiple sclerosis: A guide for rehabilitation and health care professionals (pp. 44-78). Springfield, IL: Charles C. Thomas., 2001.

[27] Rumrill P, Fraser R, Johnson K. Employment and workplace accommodation outcomes among participants in a vocational consultation service for people with multiple sclerosis. Journal of Vocational Rehabilitation 2013;39:85-90.

[28] Ketelaer P, Crijns H, Gausin J, Bouwen R. Multiple sclerosis and employment: Synthesis report. Brussels: Belgian Ministry of Labour and Employment, 1993.

[29] Duggan E, Fagan P, Yateman S. Employment factors among individuals with multiple sclerosis. Unpublished manuscript, National Multiple Sclerosis Society, 1993.

[30] Rumrill P, Roessler R, Koch L. Surveying the employment concerns of people with multiple sclerosis: A participatory action research approach. Journal of Vocational Rehabilitation 1999;12(2):75-82.

[31] Jackson M, Quaal C. Effects of multiple sclerosis on occupational and career patterns. Axon 1991, 16-22.

[32] O'Day B. Barriers for people with multiple sclerosis who want to work: A qualitative study. Journal of Neurological Rehabilitation 1998;12:139-46.

[33] LaRocca NG, Kalb R, Scheinberg LC, Kendall P. Factors associated with unemployment of patients with multiple sclerosis. Journal of Chronic Diseases 1985;38:203-10.

[34] Houser R. Chace A. Job satisfaction of people with disabilities placed through a Project with Industry. Journal of Rehabilitation 1993;59(1):45-8.
[35] Rumrill P, Roessler R. New directions in rehabilitation counseling: A career development perspective on closure. Journal of Rehabilitation 1999;65(1):26-30.

[36] Rumrill P, Roessler R, McMahon B, Fitzgerald S. Multiple sclerosis and workplace discrimination: The national Equal Employment Opportunity Commission Americans with Disabilities Act research project. Journal of Vocational Rehabilitation 2005;23(3):179-88.

[37] Unger D, Rumrill P, Roessler R, Stacklin R. A comparative analysis of employment discrimination complaints filed by people with multiple sclerosis and individuals with other disabilities. Journal of Vocational Rehabilitation 2004;20(3): 165-70.

[38] Marini I. What rehabilitation counselors should know to assist Social Security beneficiaries in becoming employed. Work: A Journal of Prevention, Assessment, and Rehabilitation 2003;21(1):37-44.

[39] Roessler R, Rumrill P. Multiple sclerosis and employment barriers: A systemic approach. Work: A Journal of Prevention, Assessment, and Rehabilitation 2003;21(1):17-23.

[40] Fraser R, McMahon B, Danczyk-Hawley C. Progression of disability benefits: A perspective on multiple sclerosis. Journal of Vocational Rehabilitation 2004;19(3):173-9.

[41] Wickert K, Dresden D, Rumrill P. The sandwich generations' guide to eldercare. New York: Demos, 2013.

[42] Graves WH. Participatory action research: A new paradigm for disability and rehabilitation research. ARCA 1991;19:8-10.

[43] Minden S, Frankel D, Hadden L, Perloff J, Srinath K, Hoaglin D. The Sonya Slifka Longitudinal Multiple Sclerosis Study: Methods and sample characteristics. Multiple Sclerosis 2006;12:24-38.

[44] Dillman D. Mail and internet surveys (2nd Ed.). Hoboken, NJ: John Wiley, 2007.

[45] Nissen S, Rumrill P. Employment and career development considerations (pp. 362-391). In B. Giesser (ed.), Primer on multiple sclerosis (Second Edition). New York: Oxford University Press, 2014.

[46] Job Accommodation Network (2014). Job Accommodation Network. Retrieved from https://askjan.org/.

[47] Wehman P. Life beyond the classroom. Baltimore, MD: Paul H. Brookes, 2006.

[48] Roessler R, Rumrill P. Enhancing productivity on your job: The 'win-win' approach to reasonable accommodations. New York: National Multiple Sclerosis Society, 2015.

[49] Simmons R, Tribe K, McDonald E. Living with multiple sclerosis: Longitudinal changes in employment and the importance of symptom management. Journal of Neurology 2010;257:926-36.

[50] Sweetland J, Riazi A, Cano S, Playford E. Vocational rehabilitation services for people with multiple sclerosis: What patients want from clinicians and employers. Multiple Sclerosis 2007;13:1183-9. 